\title{
A Genetic Animal Model of Human Neocortical Heterotopia Associated with Seizures
}

\author{
Kevin S. Lee, ${ }^{1}$ Frank Schottler, ${ }^{1}$ Jennifer L. Collins, ${ }^{1}$ Giuseppe Lanzino, ${ }^{1}$ Daniel Couture, ${ }^{1}$ Anand Rao, ${ }^{1}$ \\ Ken-ichiro Hiramatsu, ${ }^{1}$ Yasunobu Goto, ${ }^{1}$ Seung-Chyul Hong, ${ }^{1}$ Hakan Caner, ${ }^{1}$ Haruaki Yamamoto, ${ }^{1}$ \\ Zong-Fu Chen, ${ }^{1}$ Edward Bertram, ${ }^{2}$ Stuart Berr, ${ }^{3}$ Reed Omary, ${ }^{3}$ Heidi Scrable, ${ }^{4}$ Theodore Jackson, ${ }^{1}$ \\ John Goble, ${ }^{1}$ and Leonard Eisenman ${ }^{5}$
}

Departments of ${ }^{1}$ Neurological Surgery, ${ }^{2}$ Neurology, ${ }^{3}$ Radiology, and ${ }^{4}$ Neuroscience, University of Virginia Health Sciences Center, Charlottesville, Virginia 22908, and 5Department of Pathology and Anatomy, Thomas Jefferson University, Philadelphia, Pennsylvania 19107

Malformations of the human neocortex are commonly associated with developmental delays, mental retardation, and epilepsy. This study describes a novel neurologically mutant rat exhibiting a forebrain anomaly resembling the human neuronal migration disorder of double cortex. This mutant displays a telencephalic internal structural heterotopia (tish) that is inherited in an autosomal recessive manner. The bilateral heterotopia is prominent below the frontal and parietal neocortices but is rarely observed in temporal neocortex. Neurons in the heterotopia exhibit neocortical-like morphologies and send typical projections to subcortical sites; however, characteristic lamination and radial orientation are disturbed in the heterotopia. The period of neurogenesis during which cells in the heterotopia are generated is the same as in the normotopic neocortex; however, the cells in the heterotopia exhibit a "rim-to-core" neurogenetic pattern rather than the characteristic "inside-out" pat- tern observed in normotopic neocortex. Similar to the human syndrome of double cortex, some of the animals with the tish phenotype exhibit spontaneous recurrent electrographic and behavioral seizures.

The tish rat is a unique neurological mutant that shares several features with a human cortical malformation associated with epilepsy. On the basis of its regional connectivity, histological composition, and period of neurogenesis, the heterotopic region in the tish rat is neocortical in nature. This neurological mutant represents a novel model system for investigating mechanisms of aberrant neocortical development and is likely to provide insights into the cellular and molecular events contributing to seizure development in dysplastic neocortex.

Key words: cortical heterotopia; epilepsy; neuronal migration disorder; double cortex; neurogenesis; rat
Accurate development of the mammalian neocortex requires precise coordination among a myriad of cellular and molecular events. After a strictly timed phase of cellular genesis, neurons destined for the neocortex must migrate considerable distances, take positions in restricted zones, differentiate with defined orientations, and establish specific connections with various afferent and efferent targets (Rakic, 1988). Given this complex sequence of events, it is not surprising that the overall incidence of some type of cortical malformation is $>1 \%$ in the human population (Meencke and Veith, 1992). In epileptic patients, malformations of the neocortex are rather common (Meencke and Janz, 1984; Mischel et al., 1995). Some form of cortical malformation is observed in at least $14 \%$ of all cases of epilepsy (Meencke and Veith, 1992) and in $\sim 40 \%$ of severe or intractable cases (Hardiman et al., 1988; Farrell et al., 1992). Although the etiologies of cortical malformations are poorly understood, they have been

Received March 21, 1997; revised May 29, 1997; accepted June 2, 1997.

This work was supported by National Institutes of Health Grant NS34124 and National Science Foundation Grant IBN9421555 to K.S.L. We thank Mrs. Paula Keeney and Dr. H. R. Brashear for assistance with the AChE procedure, Drs. George Aldheid and Lennart Heimer for assistance with the tracing studies, and Dr. Ron Mervis (NeuroMetrix Research, Inc., Columbus, $\mathrm{OH}$ ) for processing the initial Golgi-stained material.

This paper is dedicated to Eric Lothman, whose enthusiasm and encouragement were essential for developing the tish colony.

Correspondence should be addressed to Kevin S. Lee, University of Virginia, Box 420 HSC, Charlottesville, VA 22908.

Copyright (C) 1997 Society for Neuroscience $0270-6474 / 97 / 176236-\bullet \$ 05.00 / 0$ postulated to arise from disturbances in cell proliferation, neuronal migration, and/or programmed cell death (Evrard et al., 1978; Rakic, 1988; Barkovich et al., 1992; Meencke and Veith, 1992; Mouritzen-Dam, 1992; Palmini et al., 1993; Rorke, 1994).

Our understanding of the developmental events underlying cortical malformations has been limited by the paucity of appropriate animal models for human neuronal migration disorders. Neurologically mutant animals, such as the reeler mouse, provide an important means for examining the mechanisms of disturbed cortical development (Caviness and Rakic, 1978; Caviness et al., 1988). Moreover, recent advances in the molecular genetics underlying certain neurological mutations (D'Arcangelo et al., 1995; Hirotsune et al., 1995; Ogawa et al., 1995; Rakic and Caviness, 1995) will render these animals even more valuable for clarifying basic features of normal and abnormal development of the mammalian cortex. Nonetheless, additional animal models are needed that more closely reflect the types of malformations observed in human brains. The present study describes a new neurologically mutant rat exhibiting an elemental reorganization of the telencephalon that resembles closely a neuronal migration disorder observed in certain cases of human epilepsy (Barkovich et al., 1989; Livingston and Aicardi, 1990; Vahldiek et al., 1990; Palmini et al., 1991; Ricci et al., 1992; Soucek et al., 1992; Hashimoto et al., 1993).

\section{MATERIALS AND METHODS}

Tract tracing and histological studies. All experimental protocols were approved by the University of Virginia Animal Research Committee. 
Animals used for the tract tracing experiments were anesthetized with a mixture of ketamine/xylazine $(80: 8 \mathrm{mg} / \mathrm{kg})$ and placed in a stereotaxic apparatus. The retrograde tracer Fluorogold was injected iontophoretically into the ventral basal complex of the thalamus or the cervical spinal cord. Animals were then removed from the stereotaxic apparatus and allowed to recover. Ten to eighteen days after injection, the animals were anesthetized deeply with sodium pentobarbital $(100 \mathrm{mg} / \mathrm{kg})$ and killed via perfusion fixation with $4 \%$ paraformaldehyde in $0.1 \mathrm{M}$ phosphate buffer, $\mathrm{pH}$ 7.4. Brains were removed, post-fixed in perfusion solution for 3-12 hr, and then placed in 30\% sucrose in $0.1 \mathrm{M}$ phosphate buffer until they sank. Coronal brain sections $(30-50 \mu \mathrm{m})$ were cut on a freezing microtome, mounted onto glass slides, and viewed with a fluorescence microscope. To verify anatomical loci, every sixth section was stained with cresyl violet after it was mounted.

Animals used for acetylcholinesterase (AChE) staining were killed by perfusion fixation and sectioned as described above. Unmounted sections were then processed for $\mathrm{AChE}$ according to standard techniques (Geneser-Jensen and Blackstad, 1971; Brashear et al., 1988). Sections were mounted on glass slides and inspected with a transmission microscope. Animals used for Golgi staining were killed by perfusion fixation as described above. The brains were post-fixed overnight in perfusion solution and sectioned coronally with a vibratome $(70-150 \mu \mathrm{m}$ in thickness). These sections were processed using a modified Rapid Golgi technique (Ralis et al., 1973; Landas and Phillips, 1982).

Neurogenesis studies. The adult positions of cells generated during specific stages of embryonic neurogenesis were examined by injecting 5-bromo- 2 '-deoxyuridine (BrDU) on a single embryonic day and examining the distribution of labeled cells in young adult animals. Cells in S-phase were labeled on embryonic days (E) 15-20 by administering an intraperitoneal injection of $\mathrm{BrDU}(50 \mathrm{mg} / \mathrm{kg}$ body weight) to pregnant dams. The day a vaginal plug or sperm-positive smear was identified in the dams was defined as E1. Offspring were killed between postnatal days (P) 30 and P39. Under deep sodium pentobarbital $(100 \mathrm{mg} / \mathrm{kg})$ anesthesia, animals were perfused with $2 \%$ paraformaldehyde in $0.1 \mathrm{M}$ phosphate buffer, $\mathrm{pH}$ 7.4. Brains were then removed and post-fixed for 2-7 d in perfusion solution. Brains were dehydrated, embedded in paraffin, and sectioned coronally at a thickness of $8 \mu \mathrm{m}$. Sections were mounted onto glass slides and processed for BrDU immunohistochemistry (Takahashi et al., 1992).

Monitoring of seizures. The monitoring of electroencephalographic (EEG) and behavioral activity was performed as described in detail elsewhere (Bertram and Cornett, 1993, 1994). Briefly, animals were anesthetized with ketamine/xylazine as described above and placed in a stereotaxic apparatus. A recording electrode was positioned in the normotopic frontoparietal cortex, and a reference electrode was placed near the rostral pole of the frontal lobe. Electrode pins were secured to an Amphenol connector that was then attached to the skull with dental cement. The monitoring setup uses a combined video recording system and EEG recording system with a computerized seizure detection program as described elsewhere (Bertram and Cornett, 1993, 1994). Seizure activity was evaluated off-line by examining a synchronous display of the recorded electrographic and video events.

\section{RESULTS}

\section{General appearance of the cortex of the tish rat}

The brain of this mutant animal exhibits a large region of heterotopic gray matter that is located bilaterally beneath the neocortex (Fig. 1). The heterotopic region is separated from the overlying neocortex by a thin layer of white matter, and from lower structures by a second, somewhat thicker layer of white matter. Animals exhibiting this anomaly are termed tish animals. The overall thickness of the normotopic neocortex in the vicinity of the heterotopia appears to be reduced. Mild to moderate ventriculomegaly is also observed in most tish animals. As illustrated in the three-dimensional reconstruction shown in Figure 2, the bilateral heterotopia is quite large and can extend from the frontal to occipital lobes. It is prominent in the frontal and parietal cortices but is usually absent from the temporal cortex. Although the size of this anomaly varies somewhat among affected animals, the general appearance and location of the heterotopia is quite consistent.

\section{Establishment of a breeding colony and the pattern of inheritance}

The first tish animals were identified on the basis of postmortem histological analyses during the course of unrelated experiments using a strain of Sprague Dawley rats. Attempts to establish a colony of tish animals were difficult initially because the external appearance of these animals is similar to that of normal animals. A breeding colony was established by identifying living relatives of deceased tish individuals, and then these relatives were screened using magnetic resonance imaging (MRI). The heterotopia can be resolved by using proton density MRI as a bilateral structure that is isodense to, and located below, the neocortex (Fig. 3). Crosses between affected and unaffected animals were performed to determine the pattern of inheritance of the tish trait; the outcomes of these crosses were verified using postmortem histology. In all of the breeding experiments, progeny segregated into either normal or tish phenotypes. Matings between two affected parents (incrosses) produced $100 \%$ tish progeny $(n=116$ offspring). Outcrosses between an unaffected male and an affected female (or between an affected male and an unaffected female) produced $0 \%$ affected offspring ( $n=51$ offspring). All unaffected animals used for the outcrosses were obtained from an external animal supplier. Intercrossing the offspring of these outcrosses produced 29\% (15 of 51) affected offspring. This result, together with the absence of a phenotypically distinct class of heterozygotes, indicates that tish is recessive to wild type. The overall incidences of affected males and affected females were $47 \%$ and $53 \%$, respectively. Taken together, these segregation ratios indicate an autosomal recessive pattern of inheritance and are consistent with a defect in a single gene.

\section{Histological organization}

The normotopic neocortex overlying the heterotopia is organized in a laminar manner, whereas the heterotopia lacks precise lamination (Fig. 4). Neocortical-like pyramidal neurons and various nonpyramidal neurons, including fusiform and stellate-shaped cells, are found in both the heterotopia and normotopic neocortex. The apical dendrites of the pyramidal cells in the heterotopia, however, are not consistently oriented toward the surface of the brain, and their somata do not exhibit a strict laminar organization. Some of the pyramidal neurons in the heterotopic region are inverted with their apical dendrites oriented away from the surface of the brain, whereas other cells appear to have a more conventional, i.e., radial, orientation (Fig. 4). The dendrites of pyramidal neurons located near the edge of the heterotopic region often bend to follow the contour of the region. These features contrast with the apparently normal lamination of somata and radial orientation of apical dendrites of the pyramidal cells in the normotopic neocortex (Fig. 4). The thinning of the normotopic neocortex in tish animals relative to the neocortex of unaffected animals suggests that a reduction in the overall number of cells and the extent of their arbors occurs in the affected portions of the normotopic neocortex. Unaffected parts of the neocortex and other laminar structures such as the hippocampus and cerebellum do not contain heterotopic neurons, and the laminar patterns in these regions appear normal. In sum, the histological findings indicate that the normotopic neocortex retains basic features of its normal cellular composition and organization. In contrast, the heterotopic region contains neocorticallike neurons that are positioned and oriented abnormally. 


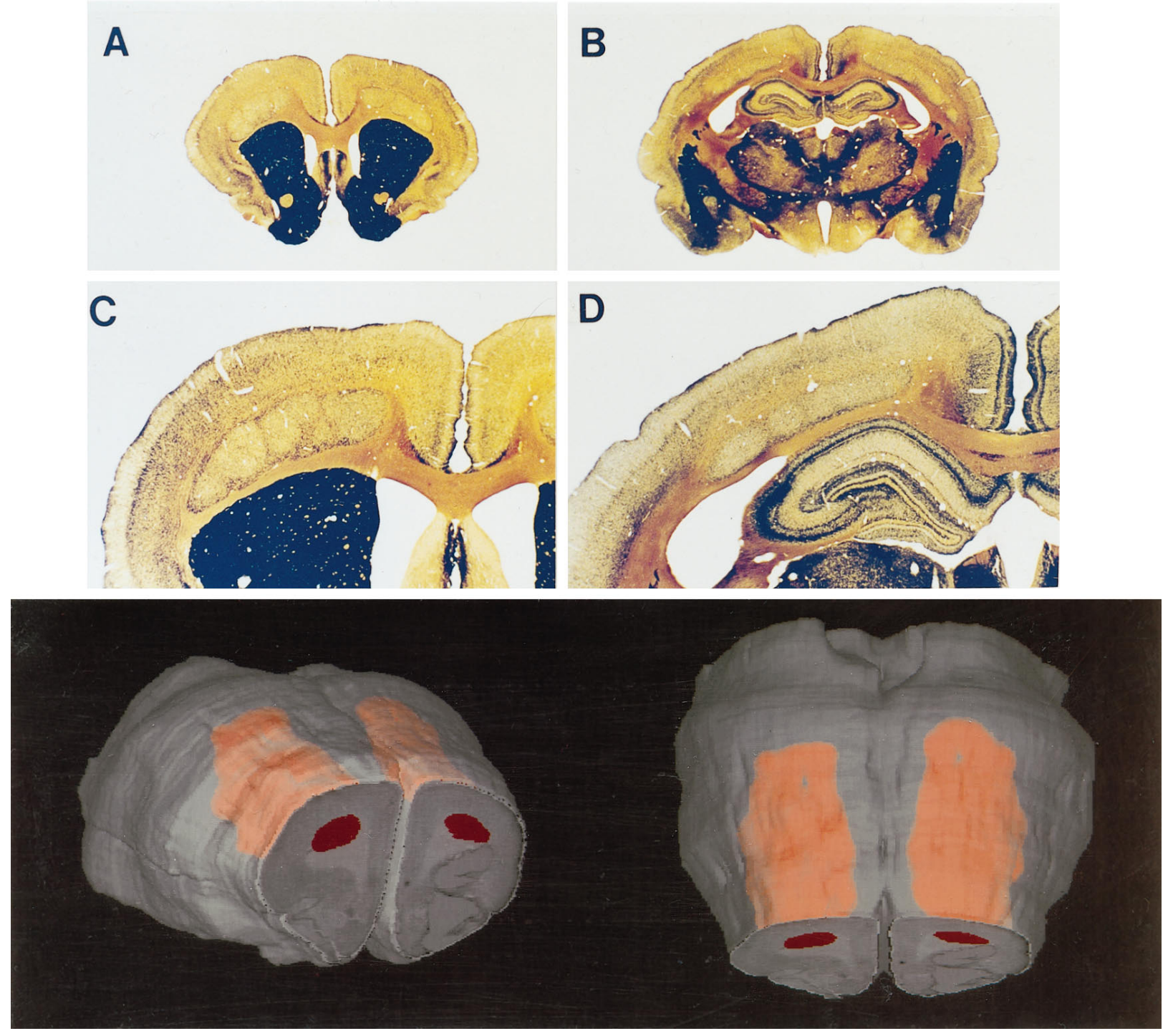

Figure 1. Top. Coronal sections of a tish brain stained for AChE. Low-magnification photomicrographs $(A, B)$ show the heterotopia to be a large bilateral structure intercalated between the neocortex and underlying white matter. A thin layer of white matter separates the heterotopia from the overlying neocortex, and a thicker layer of white matter separates it from lower structures. In $A$ and $C$, the heterotopia is located above the darkly stained striatum and below the neocortex. In the more caudal sections $(B, D)$, the heterotopia is located between the hippocampus (or lateral ventricle) and the neocortex. The heterotopia has a multinodular appearance attributable to the passage of one or more large fiber tracts through the structure.

Figure 2. Bottom. Two perspectives of a three-dimensional reconstruction of the tish brain. This figure illustrates the size and position of the heterotopia as well as its bilateral symmetry. The heterotopia is shown in red at the cut surface of the brain and in pink where it is viewed through the overlying cortex; the surrounding brain is shown in gray.

\section{Neurogenesis}

The development of the mammalian cortical plate is characterized by an inside-out pattern of neurogenesis in which latergenerated cells come to occupy more superficial positions in the adult neocortex (Angevine and Sidman, 1961). The pattern of neurogenesis in the tish brain was examined by injecting pregnant females from the tish colony with BrDU on single gestational days during neocortical neurogenesis. The animals were then allowed to survive to young adulthood (i.e., P30-P39), and labeled cells were identified immunohistochemically. Using this technique, the location of labeled cells with known birth dates can be identified in the adult cortex. Labeled cells are observed in both the normotopic neocortex and the heterotopic region of adult tish animals when BrDU is injected on E15-E20. Figure 5 shows the

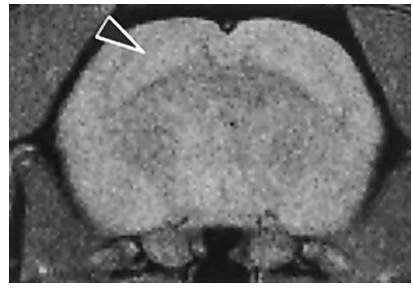

Figure 3. MR image of the tish brain. In this proton density image, the heterotopia can be observed bilaterally as an area isodense to the overlying normotopic cortex (arrowhead indicates structure on the right side of the brain). MRI was performed at the Small Aperture Magnetic Imaging and Spectroscopy Center at the University of Virginia using a 4.7 Tesla 40 $\mathrm{cm}$ bore 200/400 MR imager. 

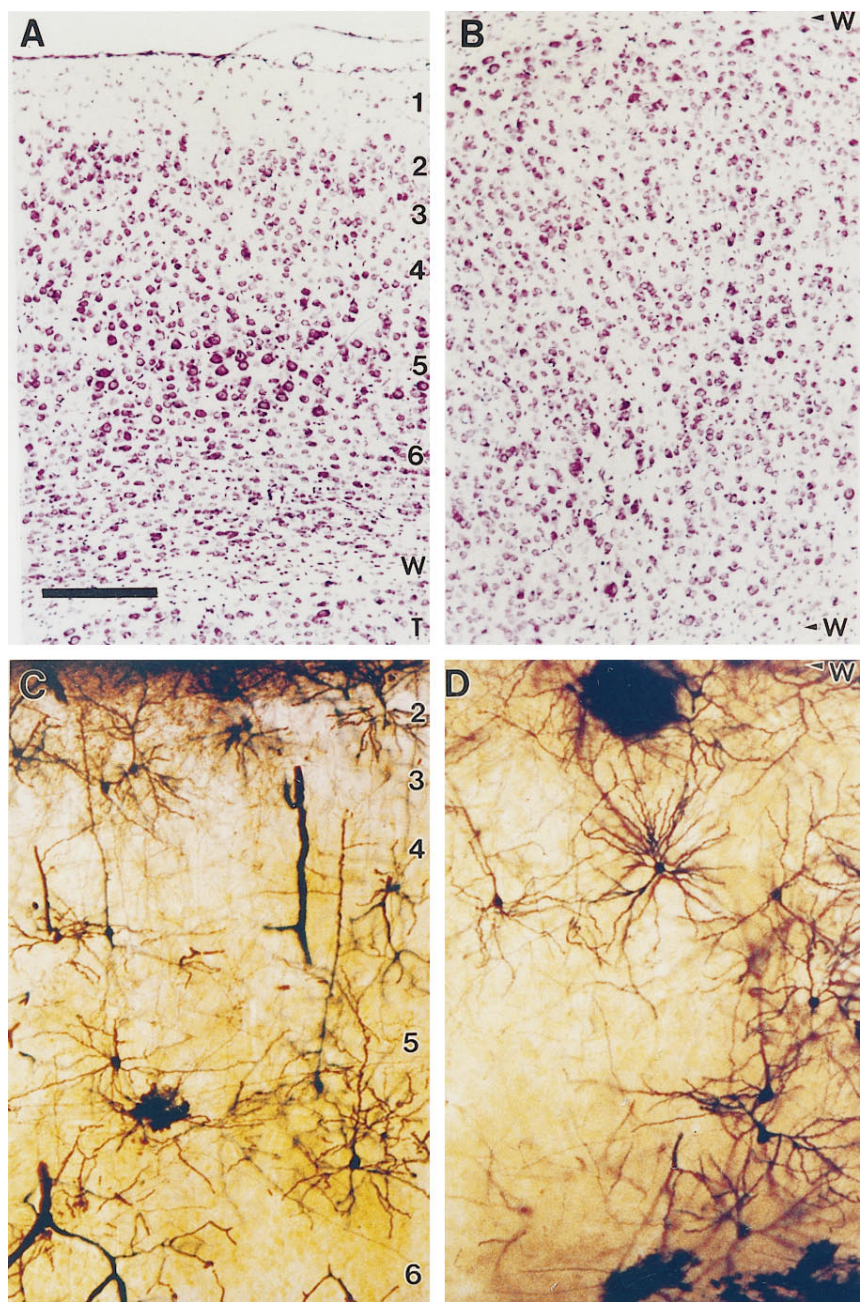

Figure 4. Histological appearance of the normotopic neocortex and heterotopic region of a tish animal. Photomicrographs of Nissl-stained sections are shown of the normotopic neocortex $(A)$ and heterotopia $(B)$. Cellular somata in the normotopic neocortex exhibit a laminar organization, whereas cells in the heterotopia do not exhibit strict lamination Golgi-stained sections of the normotopic neocortex $(C)$ and heterotopic region $(D)$ demonstrate the presence of similar cell types in the two structures. In the normotopic neocortex, the apical dendrites of pyramidal neurons are oriented radially, and their somata are located in appropriate laminae. In contrast, the neurons in the heterotopia do not exhibit a strict laminar pattern and their apical dendrites are not oriented uniformly. Numbers indicate layers of the neocortex. $W$, White matter; $T$, heterotopia. Scale bars: $A, B, 200 \mu \mathrm{m} ; C, D, 170 \mu \mathrm{m}$.

adult distribution of cells labeled by injections on E15 or E18. Cells labeled on E15 are located primarily in the deep aspect of the normotopic neocortex, whereas cells labeled on E18 are found in the superficial aspect of the normotopic neocortex. In contrast, cells labeled on E15 are concentrated along the rim (i.e., the dorsal and ventral edges) of the heterotopic region, whereas cells labeled on E18 are predominantly found in the core of the heterotopic structure. These findings indicate that the characteristic inside-out pattern of neurogenesis is intact in the normotopic neocortex of the tish mutant. The heterotopic region is composed of cells generated during the normal period of neocortical neurogenesis; however, these cells establish a rough neurogenetic gradient extending from the rim of the structure toward its core.

\section{Regional connectivity}

The preceding findings suggest that the heterotopic region of the tish brain is a neocortical entity whose structural features are not fully elaborated. This raises the possibility that the heterotopia is composed of cells that retain certain fundamental attributes of neocortical neurons despite not reaching their proper destination. Among the typical features of the neocortex are its efferent projections to subcortical targets. These include ipsilateral projections to specific thalamic nuclei, and in the case of somatosensory and motor areas, contralateral projections to the spinal cord. Previous findings in brains subjected to $\mathrm{x}$-irradiation during development indicate that some ectopic neurons can exhibit relatively normal subcortical connections (Jensen and Killackey, 1984). Neuroanatomical tracing studies were therefore undertaken to determine whether heterotopic neurons in the tish brain possess typical features of cortical connectivity. In the first series of experiments, a retrograde tracer (Fluorogold) was injected into the ventral posterolateral nucleus (VPL) of the thalamus; this portion of the thalamus receives a well characterized system of afferents from the somatosensory cortex in normal brains. In the tish mutant, retrogradely labeled cells are observed in both the somatosensory cortex and the underlying heterotopic region after injection into the VPL (Fig. 6). The labeled cells in the normotopic neocortex are located primarily in layer VI of the somatosensory cortex. The labeled cells in the heterotopia are found in the vicinity of the somatosensory cortex; these cells tend to be concentrated along the rim of the heterotopia but are also found throughout the depth of the structure (Fig. 6). These findings indicate that appropriate corticothalamic projections are formed in the normotopic neocortex and that the heterotopia also contains neurons that project topographically to the thalamus. The somata of projection cells in the normotopic cortex exhibit characteristic lamination, whereas the cells in the heterotopia are organized less strictly.

In the second series of tract tracing experiments, Fluorogold was injected unilaterally into the cervical spinal cord; this portion of the spinal cord receives afferents from somatosensory and motor cortices in normal brains. Injection of Fluorogold into the cervical spinal cord results in the retrograde labeling of large pyramidal cells contralateral to the injection site in both the normotopic neocortex and heterotopic region (Fig. 6). In the normotopic neocortex, the labeled cells are located primarily in layer $\mathrm{V}$ of somatosensory and motor cortices, and these cells exhibit a typical radial orientation of their apical dendrites (Fig. 6). Labeled neurons in the heterotopic region are found primarily in the portion of the heterotopia located below the area of normotopic cortex containing labeled cells; however, the somata of the cells do not exhibit a laminar pattern of distribution, and their apical dendrites are not uniformly oriented toward the surface of the brain (Fig. 6). Taken together, the results of the tract tracing studies demonstrate that neurons in the heterotopia provide topographically restricted afferents to appropriate subcortical targets despite their heterotopic location, improper orientation, and a failure to form restricted laminae.

\section{Seizure activity}

After the colony of tish animals had been established, behavioral seizures were observed serendipitously in some animals during the course of daily animal care. Comprehensive screening of the entire colony for the incidence of seizures has not yet been undertaken; however, spontaneous convulsive seizures have now been confirmed in 13 individuals from the colony. MRI screening 

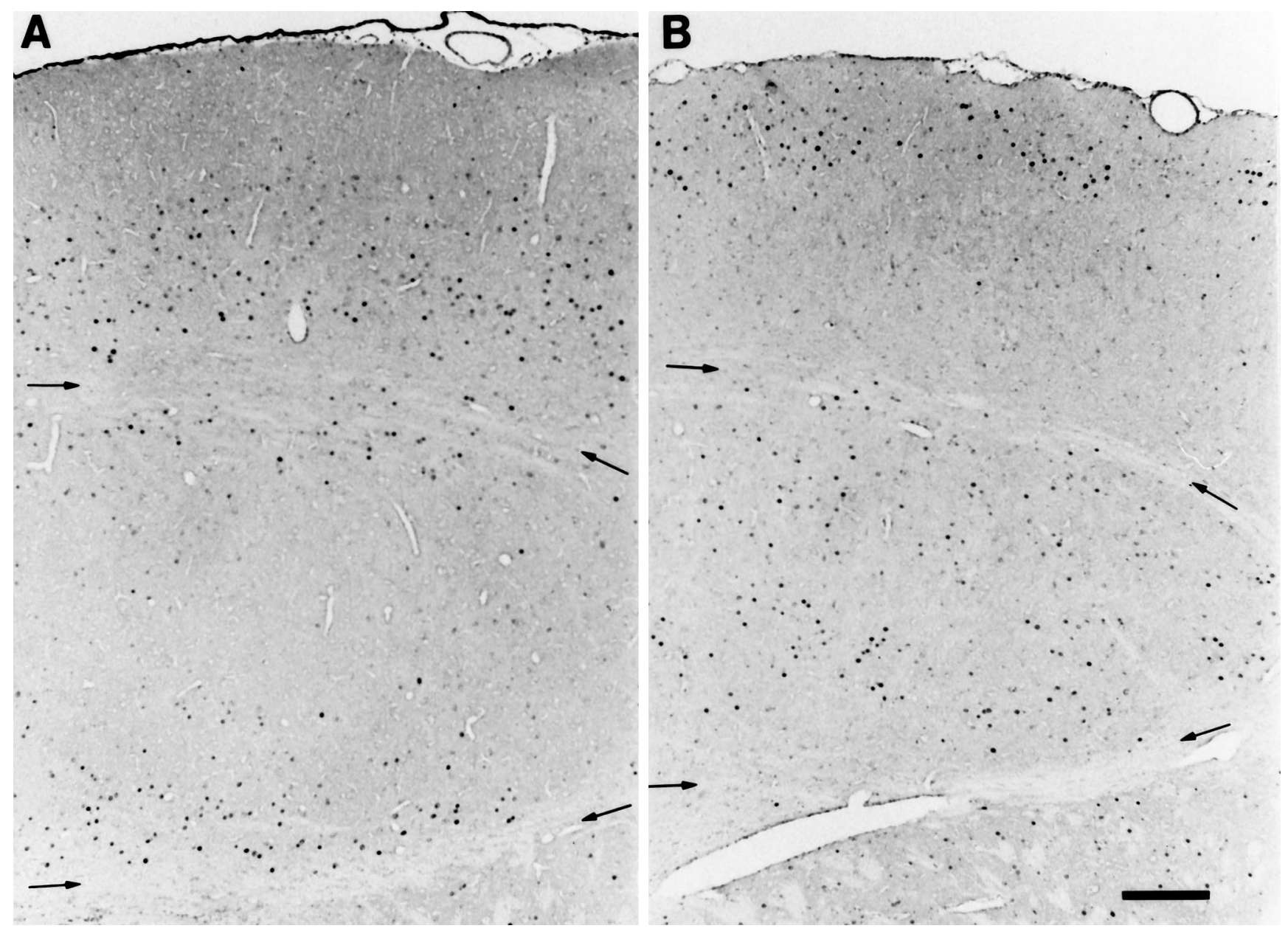

Figure 5. Neurogenetic patterns in the forebrain of the tish rat. Photomicrographs are shown of coronal sections of tish brains in which immunostaining was performed on animals labeled with BrDU on E15 $(A)$ or E18 $(B)$; these animals survived to P33 and P30, respectively. Darkly stained (BrDU-positive) cells are found primarily in the deep aspect of the normotopic neocortex in the E15-injected animal $(A)$ and in the superficial aspect of the normotopic neocortex in the E18-injected animal $(B)$. Labeled cells are located primarily in the rim of the heterotopia in the E15-injected animal $(A)$ and in the core of the heterotopia in the E18-injected animal $(B)$. Arrows indicate the white matter surrounding the heterotopic region. Scale bar, $200 \mu \mathrm{m}$.

and/or postmortem histological analyses show that the animals with seizures exhibit the tish phenotype. To further evaluate the nature of these seizures, continuous EEG and behavioral monitoring was undertaken in two of the tish animals that exhibited seizures. Electrographic and behavioral seizures occur regularly and spontaneously in these animals. In individual animals, convulsive seizure activity has been observed over a period of up to 4 months, i.e., the longest period examined. A typical EEG recording of a seizure is shown in Figure 7. The frequency of seizures in this animal is approximately 2.5 events per day, with an average seizure duration of $47 \mathrm{sec}$.

\section{DISCUSSION}

The general appearance of the cortical anomaly observed in the tish rat bears a striking resemblance to a human syndrome of cortical heterotopia that was first described over a century ago (Matell, 1893; Jacob, 1936). The human cortical anomaly is observed in certain cases of general or multifocal epilepsy and has been variously described in the literature as double cortex, band heterotopia, diffuse cortical dysplasia, or laminar heterotopia (Barkovich et al., 1989, 1992; Livingston and Aicardi, 1990; Vahldiek et al., 1990; Palmini et al., 1991, 1993; Mouritzen-Dam, 1992; Ricci et al., 1992; Soucek et al., 1992; Hashimoto et al., 1993). In these patients, a bilateral band of gray matter is observed underlying the cortical mantle and is separated from the mantle by a thin layer of white matter; a thicker layer of white matter usually separates the heterotopic region from lower structures. This anomalous region is prominent in fronto-centro-parietal areas but is less common in medial and temporal cortical areas. In addition, a mild to moderate ventriculomegaly is often associated with human double cortex. The general features of the tish brain described herein are nearly identical to those of the human syndrome of double cortex. The tish mutant thus represents a unique animal model for a human epileptic syndrome associated with cortical dysplasia.

An essential first step in understanding the character of the heterotopic region of the tish brain is to define its basic structural composition. The present findings indicate that the heterotopia is neocortical in nature. It contains neurons with neocortical-like morphology, exhibits regional connectivity characteristic of the neocortex, and is composed of cells that are generated during the normal period of neocortical neurogenesis. The developmental event(s) responsible for the formation of the heterotopia is unknown, but it may reside in an error in the migration of cells destined for the normotopic neocortex, as has been suggested for 

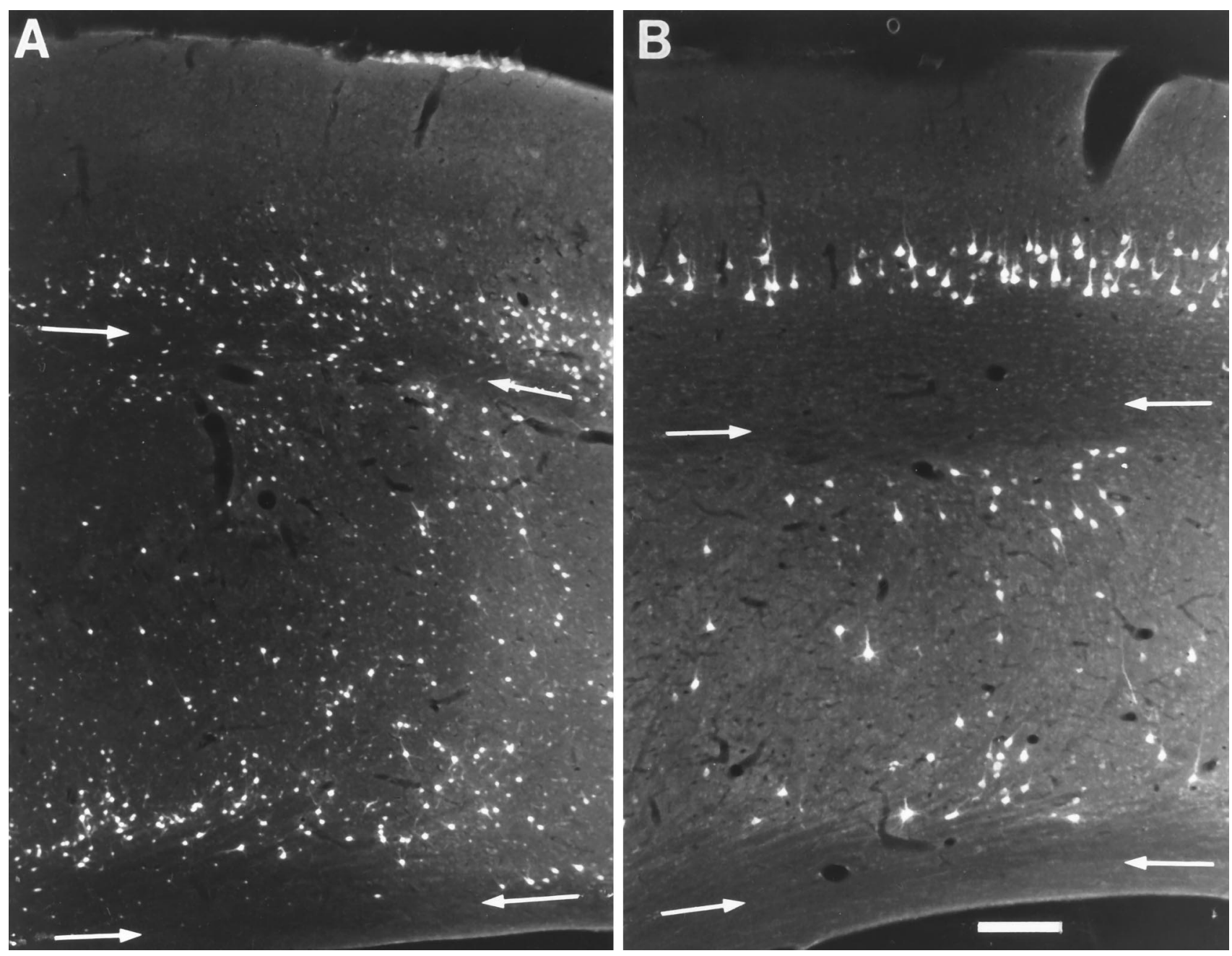

Figure 6. Subcortical connectivity of the tish forebrain. Fluorescence micrographs show retrogradely labeled projection neurons in both the normotopic neocortex and neighboring heterotopia after injection of Fluorogold into either the thalamus $(A)$ or spinal cord $(B)$. After an injection into the VPL of the thalamus $(A)$, the somata of labeled neurons in the normotopic neocortex are located primarily in layer VI, and their apical dendrites are radially oriented. Labeled cells in the heterotopic region are similar in size and appearance to those in the normotopic neocortex but are more widely dispersed and tend to be concentrated along the rim area of the heterotopia. Injection of Fluorogold into the cervical spinal cord labels large pyramidal cells in layer V of the normotopic neocortex; the apical dendrites of these cells exhibit a typical radial orientation. The heterotopia also contains retrogradely labeled pyramidal neurons; however, these cells are not laminated and their apical dendrites are not consistently oriented toward the surface of the brain. Arrows indicate the white matter surrounding the heterotopia. Scale bar, $200 \mu \mathrm{m}$.

other forms of cortical malformations (Rakic, 1988). The heterotopia does not seem to be formed by a failure in the migration of a single type of cortical cell, because (1) cells with birthdates spanning the major period of neocortical neurogenesis populate the heterotopia and (2) these cells exhibit multiple types of cortical morphology and connectivity. It remains possible, however, that an error restricted to a single type of early generated cell could cause the misplacement of all classes of subsequently generated cells. It is important to note that the normotopic neocortex of this mutant animal, although reduced in thickness, exhibits a relatively normal pattern of organization; this suggests that the elaborate sequence of events required to produce normal neocortical organization is relatively intact in the telencephalon of the developing mutant animal. The absence of heterotopic cells in the hippocampus or cerebellum indicates that the developmental error responsible for the tish phenotype is specific to neocortical development. Moreover, the absence of heterotopic cells in temporal neocortex indicates that all neocortical regions are not uniformly impacted by the mutation. This raises the possibility
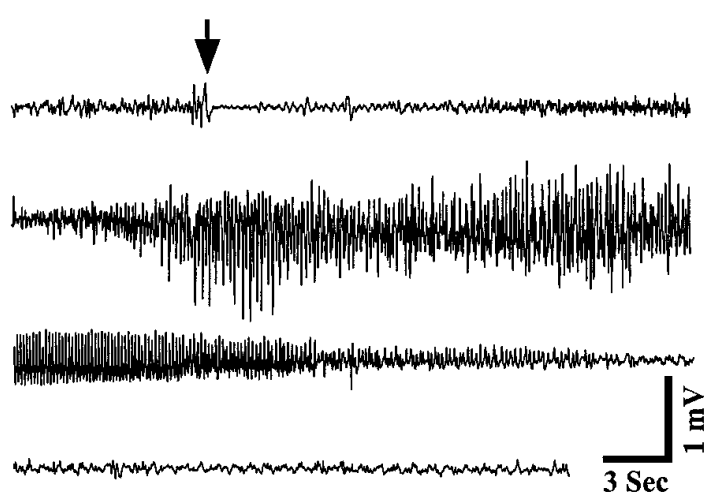

Figure 7. Electroencephalographic recordings of a seizure in a tish rat. The four lines represent a continuous EEG recording from a single electrode positioned in the normotopic neocortex. Seizure activity can be observed as changes in the frequency and amplitude of the EEG; this event lasted $\sim 63 \mathrm{sec}$. The animal exhibited convulsive behavioral seizures during the electrographic seizure event (arrow indicates seizure onset). 
that the proliferating cells affected by the mutation may be confined to a restricted part of the ventricular zone responsible for neocortical neurogenesis.

The tish malformation may not result strictly from an error in neuronal migration but could arise from a disturbance in any of the events necessary for normal corticogenesis. For example, alterations in cellular proliferation (Eksioglu et al., 1996) and programmed cell death (Kuida et al., 1996) have been postulated to participate in the formation of heterotopic masses of cells in the neocortex. The roles of cellular proliferation, neuronal migration, and programmed cell death in the development of double cortex are unclear; however, the tish rat should provide a useful model system with which to evaluate the relative contributions of these key mechanisms.

The functional role of the tish region is unknown but is an intriguing topic for speculation. It is conceivable that the heterotopia represents a second or parallel cortex that duplicates the connections and functions of the normotopic neocortex. Another possibility is that the novel brain region is atavistic in nature and reflects a more primitive form of cortical organization. The presence of electrographic and behavioral seizures in these animals suggests that the electrophysiological function of this region may be fundamentally disturbed. Although the precise role of heterotopic neurons in the expression of seizure activity in tish animals remains to be established, it is noteworthy that heterotopic cortical neurons are commonly found in the brains of intractable epileptic patients. Future investigations should be able to take advantage of the tish mutant to evaluate the role of misplaced cortical cells in the etiology of seizure activity and to elucidate the underlying mechanisms of neuronal migration disorders.

\section{REFERENCES}

Angevine JB, Sidman RL (1961) Autoradiographic study of cell migration during histogenesis of cerebral cortex in the mouse. Nature 192:766-768.

Barkovich AJ, Jackson DE, Boyer RS (1989) Band heterotopias: a newly recognized neuronal migration anomaly. Radiology 171:455-458.

Barkovich AJ, Gressens P, Evrard P (1992) Formation, maturation, and disorders of brain neocortex. Am J Neuroradiol 13:423-446.

Bertram EH, Cornett J (1993) The ontogeny of seizures in a rat model of limbic epilepsy: evidence for a kindling process in the development of chronic spontaneous seizures. Brain Res 625:295-300.

Bertram EH, Cornett J (1994) The evolution of a rat model of chronic spontaneous limbic seizures. Brain Res 661:157-162.

Brashear HR, Godec MS, Carlsen J (1988) The distribution of neuritic plaques and acetylcholinesterase staining in the amygdala in Alzheimer's disease. Neurology 38:1694-1699.

Caviness VS, Rakic P (1978) Mechanisms of cortical development: a view from mutations in mice. Annu Rev Neurosci 1:297-326.

Caviness VS, Crandall JE, Edwards MA (1988) The reeler malformation: implications for neocortical histogenesis. In: Cerebral cortex, Vol 7 (Peters A, Jones E, eds), pp 59-89. New York: Plenum.

D'Arcangelo G, Miao GG, Chen SC, Soares HD, Morgan JI, Curran T (1995) A protein related to extracellular matrix proteins deleted in the mouse mutant reeler. Nature 374:719-723.

Eksioglu YZ, Scheffer IE, Cardenas P, Knoll J, DiMario F, Ramsby G, Berg M, Kamuro K, Berkovic SF, Duyk M, Parisi J, Huttenlocher PR, Walsh CA (1996) Periventricular heterotopia: an X-linked dominant epilepsy locus causing aberrant cerebral cortical development. Neuron 16:77-87.

Evrard P, Caviness VS, Prats-Vinas J, Lyon G (1978) The mechanism of arrest of neuronal migration in the Zellweger malformation: an hypothesis based upon cytoarchitectonic analysis. Acta Neuropathol (Berl) 41:109-117.

Farrell MA, DeRosa MJ, Curran JG, Lenard Secor D, Cornford ME, Comair YG, Peacock WJ, Shileds WD, Vinters HV (1992) Neuropathologic findings in cortical resections (including hemispherectomies) performed for the treatment of intractable childhood epilepsy. Acta Neuropathol (Berl) 83:246-259.
Geneser-Jensen FA, Blackstad TW (1971) Distribution of acetyl cholinesterase in the hippocampal region of the guinea pig. I. Entorhinal area, parasubiculum, and presubiculum. Z Zellforsch 114:460-481.

Hardiman O, Burke T, Phillips J, Murphy S, O’Moore B, Staunton H, Farrell MA (1988) Microdysgenesis in resected temporal neocortex: incidence and clinical significance in focal epilepsy. Neurology 38: 1041-1047.

Hashimoto R, Seki T, Takuma Y, Suzuki N (1993) The “double cortex' syndrome on MRI. Brain Dev 15:57-59.

Hirotsune S, Takahara T, Sasaki N, Hirose K, Yoshiki A, Ohashi T, Kusakabe M, Murakami Y, Muramatsu M, Watanabe S, Nakao K, Katsuki M, Hayashizaki Y (1995) The reeler gene encodes a protein with an EGF-like motif expressed by pioneer neurons. Nature Genet 10:77-83.

Jacob H (1936) Faktoren bei der Entstehung der normalen und entwicklungsgestorten Hirnrinde. Ztschr f d ges Neurol U Psych 155:1-39.

Jensen KF, Killackey HP (1984) Subcortical projections from ectopic neocortical neurons. Proc Natl Acad Sci USA 81:964-968.

Kuida K, Zheng TS, Na S, Kuan C, Yang D, Karasuyama H, Rakic P, Flavell RA (1996) Decreased apoptosis in the brain and premature lethality in CPP32-deficient mice. Nature 384:368-372.

Landas S, Phillips MI (1982) Staining of human and rat brain vibratome sections by a new Golgi method. J Neurosci Methods 5:147-151.

Livingston J, Aicardi J (1990) Unusual MRI appearance of diffuse subcortical heterotopia or "double cortex" in two children. J Neurol Neurosurg Psychiatry 53:617-620.

Matell M (1893) Ein Fall von Heterotopie der grauen Substanz in den beiden Hemispheren des Grosshirns. Arch Psychiatr Nervenkr 25: 124-136.

Meencke H, Janz D (1984) Neuropathological findings in primary generalized epilepsy: a study of eight cases. Epilepsia 25:8-21.

Meencke H, Veith G (1992) Migration disturbances in epilepsy. Epilepsy Res [Suppl] 9:31-40.

Mischel PS, Nguyen LP, Vinters HV (1995) Cerebral cortical dysplasia associated with pediatric epilepsy: review of neuropathologic features and proposal for a grading system. J Neuropathol Exp Neurol 54:137-153.

Mouritzen-Dam A (1992) The possible pathological importance of dysgenesis, heterotopia and other cellular displacements in the brain. Epilepsy Res [Suppl] 9:61-65.

Ogawa M, Miyata T, Nakajima K, Yagyu K, Seike M, Ikenaka K, Yamamoto H, Mikoshiba K (1995) The reeler gene-associated antigen on Cajal-Retzius neurons is a crucial molecule for laminar organization of cortical neurons. Neuron 14:899-912.

Palmini A, Andermann F, Aicardi J, Dulac O, Chaves F, Ponsot G, Pinard JM, Goutieres F, Livingston J, Tampieri D, Andermann E, Robitaille Y (1991) Diffuse cortical dysplasia, or the "double cortex" syndrome: the clinical and epileptic spectrum in 10 patients. Neurology 41:1656-1662.

Palmini A, Andermann F, de Grissac H, Tampieri D, Robitaille Y, Langevin P, Desbiens R, Andermann E (1993) Stages and patterns of centrifugal arrest of diffuse neuronal migration disorders. Dev Med Child Neurol 35:331-339.

Rakic P (1988) Defects of neuronal migration and the pathogenesis of cortical malformations. Prog Brain Res 73:15-37.

Rakic P, Caviness VS (1995) Cortical development: view from neurological mutants two decades later. Neuron 14:1101-1104.

Ralis HM, Beesley RA, Ralis ZA (1973) Techniques in neurohistology. London: Butterworth.

Ricci S, Cusmai R, Fariello G, Fusco L, Vigevano F (1992) Double cortex: a neuronal migration anomaly as a possible cause of LennoxGastaut syndrome. Arch Neurol 49:61-64.

Rorke LB (1994) A perspective: the role of disordered genetic control of neurogenesis in the pathogenesis of migration disorders. J Neuropathol Exp Neurol 53:105-117.

Soucek D, Birbamer G, Luef G, Felber S, Kristmann E, Bauer G (1992) Laminar heterotopic grey matter (double cortex) in a patient with late onset Lennox-Gastaut syndrome. Wien Klin Wochenschr 104:607-608.

Takahashi T, Nowakowski RS, Caviness VS (1992) BUdR as an S-phase marker for quantitative studies of cytokinetic behaviour in the murine cerebral ventricular zone. J Neurocytol 21:185-197.

Vahldiek G, Terwey B, Hanefeld F, Sperner J (1990) Magnetic resonance tomography of laminar heterotopia. Fortschr Roentgenstr 152: $378-383$. 